\title{
The study of the FDM technology of 3D printing with the use of materials for production tooling
}

\author{
Anastasia Koshkina ${ }^{1,}{ }^{*}$, Alexander Fedorov ${ }^{1}$, Alexander Morozov ${ }^{2}$, Evgeny Karpukhin ${ }^{1}$, and \\ Yulia Poletaeva ${ }^{1}$ \\ ${ }^{1}$ Federal State Budgetary Educational Institution of Higher Education Ulyanovsk State Tecnical \\ University, Ulyanovsk, Russian Federation \\ ${ }^{2}$ Federal State Budgetary Educational Institution of Higher Education Ulyanovsk State Agrarian \\ University, Ulyanovsk, Russian Federation
}

\begin{abstract}
The paper presents a comprehensive study of the surfaces of plastic samples $(90 \%$ polysulfone (PSU) $+10 \%$ polycarbonate $(\mathrm{PC}))$ modified with the help of an ultrasonic resonator to reduce friction in contact between the material of aluminum skins and a covering puncheon. Comparative characteristics of surfaces have been obtained, such as: microhardness, coefficient of friction and wear resistance in contact with wrought aluminum alloy D16T.
\end{abstract}

\section{Introduction}

One of the tendencies of modern aircraft construction is to reduce costs for technological preparation of production. Proceeding from the fact that in the technological preparation of production about $60 \%$ of the expenditures are spent on production tooling, it is important to reduce its cost. One of the ways to reduce the cost of production tooling is to ensure its versatility with the use of new polymeric materials.

The distinctive feature of production tooling proposed by the authors is that the replaceable casing will be made by 3D printing from plastic that contains $90 \%$ of polysulfone and $10 \%$ of polycarbonate. Hereinafter, this plastic will be referred to as PSU + PC further in the text. The PSU + PC plastic proposed by the authors of the paper has good mechanical properties, namely, the bending stress during deflection is $100 \mathrm{MPa}$ and the modulus of elasticity in bending is $6800 \mathrm{MPa}$. This plastic has recently been actively used in aircraft construction, as a material for aircraft components. Also, 3D printing gives an opportunity to print casings with a thickness of more than $10 \mathrm{~mm}$, while the maximum thickness of fiberglass is $10 \mathrm{~mm}$ [1].

The most common problem in the manufacturing of skins using the method of stretching is high friction between the workpiece and tooling. The use of fiberglass solves the problem of high friction, while the application of PSU + PC has not been studied yet.

\footnotetext{
*Corresponding author: fallen0008@mail.ru
} 


\section{Methodology of Researches}

The study of the modified surfaces of samples was carried out by a comparative analysis of the following characteristics:

- coefficient of friction;

- wear resistance;

- Vickers microhardness HV.

The friction coefficient was determined on a friction machine MTU-01 TU 4271-00129034600-2004 according to the "ring in a plane" scheme. In this scheme, the rotating ring is pressed against a stationary sample in the horizontal plane, with the aim to turn it. The test scheme is presented in the textbook [2]. A sample of wrought aluminum alloy D16T was used as the ring. The surface of the sample made of PSU + PC plastic was used as a "plane". Further in the text a plastic sample will be called a "counter-body". The tests were carried out at a pressure of $31000 \mathrm{~Pa}$, as well as the ring rotation speed $\mathrm{V}$ equal to $200 \mathrm{rpm}$ (taking account of the ring geometry of $0.157 \mathrm{~m} / \mathrm{s}$ ).

Wear resistance is understood as the property of a material to resist wear under certain conditions of friction, assessed by the inverse rate or intensity of wear [2]. In this work, wear resistance I was calculated from the wear rate

$$
\mathrm{N}=\mathrm{I} / \mathrm{N}
$$

The intensity of wear I was determined according to GOST(state standard) 23.224-86.

$$
\mathrm{I}=\mathrm{W} / \mathrm{L}
$$

The samples were weighed before and after testing on a friction machine, thereby finding the value of the change in the mass $\Delta \mathrm{G}$. Knowing the time under load and the rotation speed of a sample the path of friction $\mathrm{L}$ was calculated.

$$
\mathrm{L}=\mathrm{V} \cdot \mathrm{t}
$$

Linear wear of a sample W was calculated according the technique from GOST(state standard) 23.224-86.

$$
W=\frac{\Delta G}{\gamma A}
$$

where $\gamma$ - the density of the worn material, $\mathrm{kg} / \mathrm{m} 3$;

$\mathrm{A}$ - the contour area of the contact between samples, $\mathrm{m} 2$.

The obtained value of wear resistance was correlated with the table of wear resistance classes from the textbook [2].

The microhardness was determined on a PMT LOMO-3M microhardness tester by the Vickers method in accordance with GOST (state standard) 9450-76.

After determining the mechanical and tribotechnical properties of the plastic, a static analysis of the design of a covering puncheon was carried out. The normal load $\mathrm{P}$ on the working surface of the covering puncheon was determined by the formula

$$
\mathrm{P}=2 \cdot \mathrm{K} \cdot \mathrm{Bb} \cdot \delta \cdot \sigma \mathrm{UTS}
$$

where $\mathrm{K}$ - safety factor of a covering puncheon taken as 1,5 ;

$\mathrm{Bb}$ - width of a sheet workpiece, $\mathrm{mm}$;

$\delta$ - thickness of a sheet workpiece, $\mathrm{mm}$;

бUTS - tensile stress limit for uniaxial stretching of a sheet workpiece, MPa. 
The static analysis of the design of a covering puncheon was performed using Nastran with the finite element method.

Samples were made for tribotechnical tests (Fig. 1)

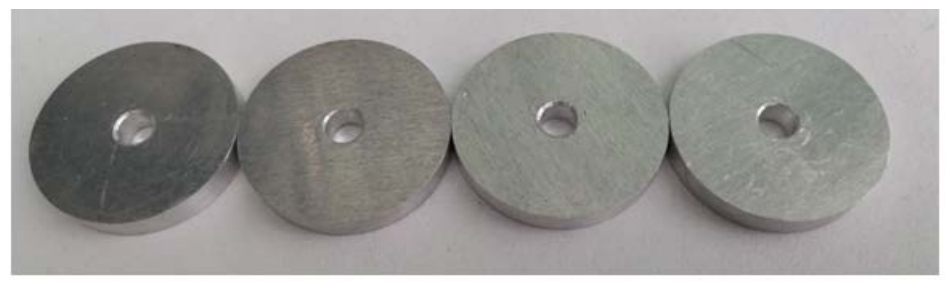

Revolving D16T aluminum samples

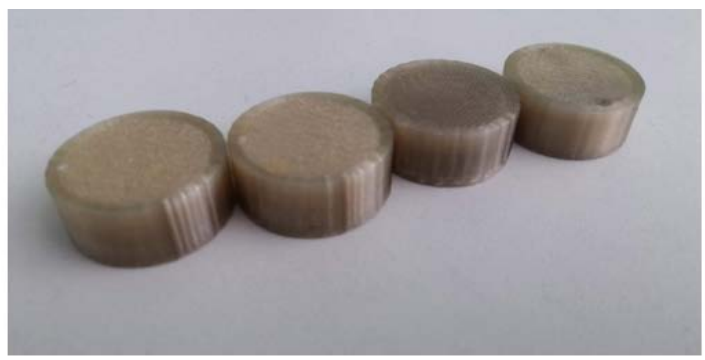

Fixed PSU $+P C$ samples (stretch forming die fragment)

Fig. 1. Samples for tribotechnical tests

The rings were made of wrought aluminum alloy D16T, and the counter-bodies were made of PSU + PC plastic. Tribotechnical tests were carried out on an MTU-01 friction machine.

\section{Research Results and Discussion}

The results of measuring the coefficient of friction are shown in Figure 2.

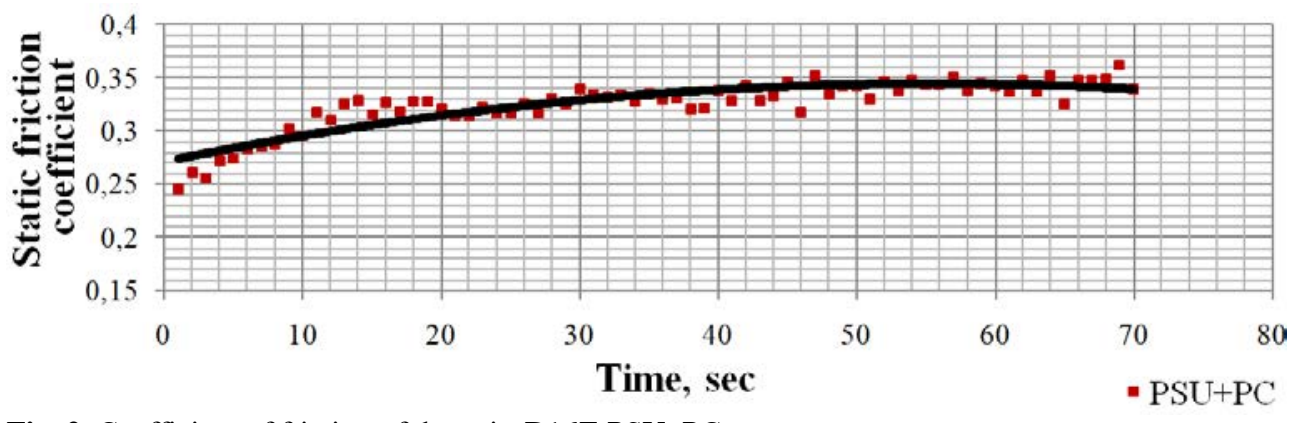

Fig. 2. Coefficient of friction of the pair: D16T-PSU+PC

As a result of the experiment, it was found that when the PSU + PC plastic comes into contact with aluminum alloy D16T, high friction forces arise. On average, the vertical action moment is $0.1125 \mathrm{~N} \cdot \mathrm{m}$, while the frictional moment is $0.033 \mathrm{~N} \cdot \mathrm{m}$. The resulting coefficient of friction is $0.29 \ldots 0.34$. This value of the coefficient of friction is equal to the 
reference value of the friction coefficient of pairs of two aluminum alloys. For example, the coefficient of friction of a pair of foreign aluminum alloys 6061 is 0.34 [3].

A high value of the coefficient of friction leads to an uneven distribution of deformations of the thinning of the workpiece during stretching, as well as the appearance of corrugations and scratches on it. This circumstance leads to the loss of the uniform strength of the finished product - the skin.

Wear resistance and surfaces of the counter-body made of PSU + PC plastic is 8.628 . 107 , which corresponds to the 7 th class of wear resistance.

The microhardness of the counter-body surface made of PSU + PC plastic was HV 14.0 ... 14.8, while the value of the microhardness of the AD35 cladding on the ring made of wrought aluminum D16T is HV 25.7 ... 25.9. Accordingly, the microhardness of PSU + PC plastic is $39 \%$ lower than that of $\mathrm{AD} 35$ cladding deposited on wrought aluminum alloy D16T.

To apply PSU + PC plastic as a material for the casing of a universal re-adjusted covering puncheon, a surface modification or its lubrication is required before each shaping. The stretching process is, in most cases, a multi-stage operation. Between these stages, as a rule, the workpiece is heat treated. Therefore, the use of a lubricant to create favorable friction conditions is not advisable due to the length of the stretching process, since it adds an extra operation to remove it before heat treatment. Therefore, the authors took a decision to modify the surface of PSU + PC plastic with molybdenum disulfide by means of the surface modification in an ultrasonic resonator. The technique according to which the modification was performed is described in the papers [4, 5].

As a result of the modification, the samples were obtained in the form (Fig. 3).
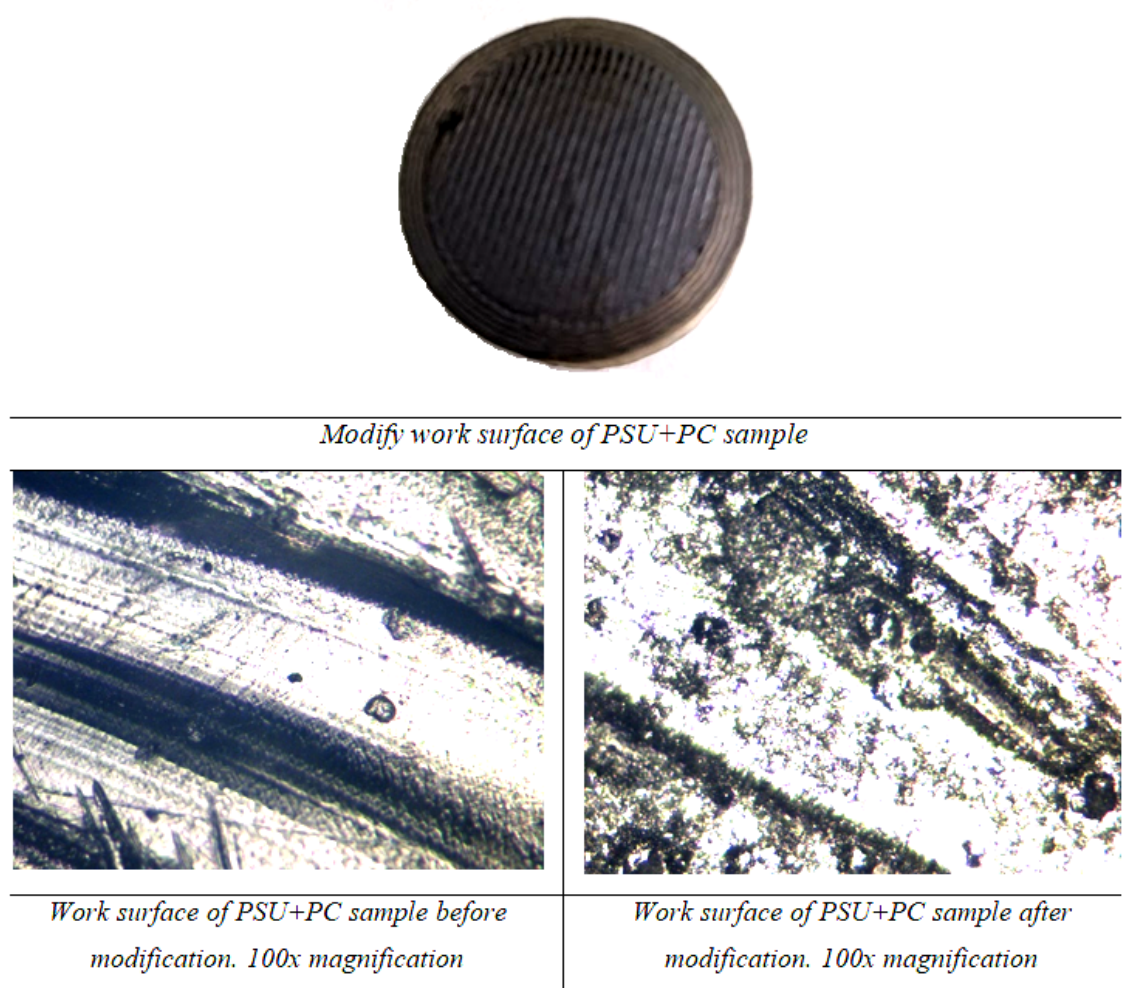

Fig. 3. Photo of the surface of the counter-body made of PSU + PC with 100x magnification 
Mechanical tests of the modified samples were carried out using an MTU-01 friction machine at constant pressure and rotational speed with the determination of the friction coefficient. A comparative graph has been constructed to demonstrate the relationship between the friction coefficients and the contact time of the D16T ring with pure PSU + PC plastic and the contact of the D16T ring with PSU + PC plastic, the surface of which is modified with molybdenum disulfide (Fig. 4).

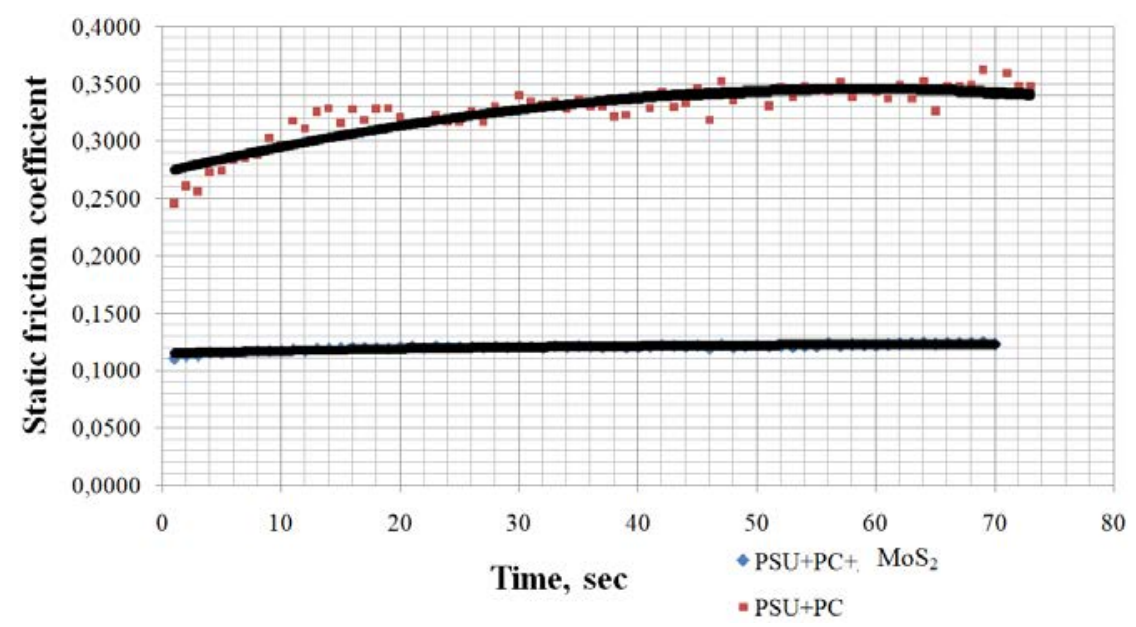

Fig. 4. Comparative graph of the change in the coefficient of friction of pairs:

where - D16T-PSU+PC, with a surface modified with molybdenum disulfide;

- D16T-PSU+PC

The use of the surface modification with molybdenum disulfide significantly reduced the coefficient of friction from $0.29 \ldots 0.34$ to $0.10 \ldots 0.11$.

The wear resistance of the surface of the counter-body made of PSU + PC plastic modified with molybdenum disulfide is $2.224 \cdot 108$, which corresponds to the $8^{\text {th }}$ wear resistance class.

The microhardness of the surface modified with molybdenum disulfide of the counterbody made of PSU + PC plastic was HV 19.0 ... 20.6.

The final comparison of the measured characteristics of plastics is shown in Table 1.

Table 1. Characteristics of PSU + PC plastic in contact with aluminum alloy D16T.

\begin{tabular}{|l|c|c|}
\hline \multicolumn{1}{|c|}{ Indicators } & $\begin{array}{c}\text { The surface of the } \\
\text { counter-body made } \\
\text { of PSU+PC is not } \\
\text { modified }\end{array}$ & $\begin{array}{c}\text { The surface of the counter-body } \\
\text { made of PSU+PC is modified with } \\
\text { molybdenum disulfide }\end{array}$ \\
\hline Coefficient of friction & $0,29 \ldots 0,34$ & $0,10 \ldots 0,11$ \\
\hline $\begin{array}{l}\text { Class of wear } \\
\text { resistence }\end{array}$ & 7 & 8 \\
\hline $\begin{array}{l}\text { Vickers } \\
\text { microhardiness HV }\end{array}$ & $14,0 \ldots 14,8$ & $19,0 \ldots 20,6$ \\
\hline
\end{tabular}

Thus, the modification of the surface of a plastic consisting of $90 \%$ polysulfone and $10 \%$ polycarbonate with molybdenum disulfide using the method of the surface plastic deformation in an ultrasonic resonator made it possible to:

- to increase the class of wear resistance of the material; 
- to reduce the coefficient of friction by $67 \%$ from $0.29 \ldots 0.34$ to $0.1 \ldots 0.11$;

- to increase the surface microhardness by $26 \%$ from HV $14 \ldots 14.8$ to HV 19 ... 20.6.

These improvements were verified only through mechanical contact with wrought aluminum alloy D16T.

\section{Conclusion}

For the purpose of reducing friction, a way was proposed to modify the working surface of a covering puncheon with molybdenum disulfide by means of an ultrasonic resonator.

It should be pointed out that in the future, the authors are also going to study other methods of modifying the surface and materials. So far, the results have been obtained only for molybdenum disulfide. The next step is to explore how deeply the material penetrates when modified with the use of an ultrasonic resonator, as well as what happens to the surface later.

\section{References}

1. Bogolyubov, V.S. Shaping equipment made of polymeric materials. (Moscow, Mashinostroenie, 1979)

2. Penkin, N.S Penkin, A.N. Serbin, V.M. Fundamentals of tribology and tribotechnics (Moscow, Mashinostroenie, 2008)

4. Blau, P.J. Friction science and technology: from concepts to applications (CRC Press, Boca Raton, 2009)

4. Salaev, R.A. Fedorov, A.A. Mukhin, D.V. Method of hardening carbon tapes with modified nanotubes based on the use of ultrasonic resonators (Bulletin of the Samara Scientific Center of the Russian Academy of Sciences. 2019)

5. Mukhin, D.V. Fedorov, A.A. Salaev, R.A. Research into the possibility of increasing the absorption capacity of metals to IR radiation by creating a surface composite layer saturated with nanomaterials (Izvestiya of the Samara Scientific Center of the Russian Academy of Sciences, 2019) 